\title{
CAPACITAÇÃO DISCENTE NO PROCESSO DE TRABALHO EM DIAGNÓSTICO POR IMAGEM DO TÉCNICO EM ENFERMAGEM
}

\author{
TRAINING NURSING TECHNICIAN STUDENTS IN THE PROCESS OF WORKING WITH DIAGNOSTIC IMAGING \\ CAPACITACIÓN DISCENTE EN EL PROCESO DE TRABAJO EN DIAGNÓSTICO POR IMAGEN DEL TÉCNICO \\ EN ENFERMERÍA
}

\author{
Juliana Almeida Coelho ${ }^{1}$ \\ Franciele Cardoso de Vargas ${ }^{2}$
}

Resumo A atuação da enfermagem radiológica cresceu significativamente, tornando esse profissional um elemento integral na radiologia e no diagnóstico por imagem. Considerando que um profissional com fragilidades em sua qualificação expõe-se a riscos desnecessários, a importância deste trabalho é resultado da necessidade de disseminar conhecimentos acerca da especialidade a futuros profissionais. O objetivo deste artigo é conhecer o processo de trabalho em diagnóstico por imagem dos discentes do Curso Técnico em Enfermagem-Proeja, em uma instituição pública da Grande Florianópolis, no estado de Santa Catarina. A metodologia utilizada foi a pesquisa-ação. Aplicaram-se três questionários aos discentes e docentes do curso, a fim de conhecer as necessidades do curso em relação ao tema. Os resultados revelaram uma defasagem na formação, visto que a temática não é abordada nas aulas. Com base nas necessidades expostas pelos participantes da pesquisa, as ações de capacitação foram planejadas, abordando temas como radiação ionizante, proteção radiológica, atuação do técnico em enfermagem na área e legislação. Após a capacitação, os alunos mostraram maior segurança e interesse em atuar nos serviços de diagnóstico por imagem, bem como em manter um processo de educação continuada. Sendo assim, a realização da capacitação mostrou-se pertinente à formação dos futuros profissionais.

Palavras-chave radiologia; educação em enfermagem; trabalho.
Abstract The role played by radiologic nursing has grown significantly, rendering this professional an integral element of radiology and of diagnostic imaging. Since a professional with flaws in training is exposed to unnecessary risks, the importance of this work is the outcome of the need to disseminate knowledge about this area of expertise to future professionals. The purpose of this article is to get to know the diagnostic imaging work process offered to the students of the Technical Course in Nursing-Proeja at a public institution in the Metropolitan Region of Florianópolis, state of Santa Catarina. Action research was the methodology used. Three questionnaires were applied to course students and faculty in order to learn more about the needs of the course insofar as this topic is concerned. The results revealed a lag in training, since the subject is not addressed in class. Based on the needs shown by the research subjects, the training activities were planned in such a manner as to cover topics related to ionizing radiation, protection against radiation, the work of the nursing technician in this area, and the legislation. After the training, students showed greater security and interest in working with diagnostic imaging services as well as in maintaining a continuing education process. Thus, providing the training proved to be relevant to qualifying future professionals.

Keywords radiology; nursing education; work. 


\section{Introdução}

Desde o final do século XX, novos desafios para a formação profissional em saúde vêm surgindo. Em grande parte isso se deve à aceleração das transformações no mundo do trabalho. Como consequência, esse cenário também vem provocando transformações no mundo acadêmico no que se refere às exigências de capacitação e atualização, e nos processos formativos desenvolvidos (Haddad et al., 2006; Vasconcellos, 2006; Delors et al., 2000).

No setor saúde, tanto público quanto privado, a assistência profissional é realizada por diversas categorias profissionais, entre elas a enfermagem, regulamentada pela lei federal n. 7.498, de 25 de junho de 1986.

Uma prova da importância dessa categoria profissional dentro dos estabelecimentos de saúde está no fato de que, de acordo com Pires, "ninguém é atendido em um serviço de saúde de média complexidade sem que a enfermagem tenha direta ou indiretamente influência no resultado da assistência recebida" (Pires, 2009, p. 742).

Todavia, as ações do enfermeiro na área da saúde não são resumidas apenas nos cuidados tradicionalmente conhecidos. $\mathrm{O}$ trabalho realizado por esses profissionais é bastante diversificado, por isso ele é impulsionado na busca contínua por atualizações dentro da área tecnológica, com o objetivo de ampliar seus conhecimentos e habilidades e, também, de acompanhar os avanços tecnológicos, tornando, assim, a sua atuação mais especializada dentro do setor (Sales et al., 2010).

Dentro da abrangência dessa profissão, surge um novo campo para a atuação do enfermeiro no ambiente hospitalar: a radiologia. Os serviços de radiologia compreendem três áreas de atuação: radiodiagnóstico, radioterapia e medicina nuclear. Em todas elas, há exposição dos profissionais da saúde a radiações ionizantes. Isso implica a utilização correta de equipamentos de proteção individual (EPIs) e plumbíferos, e no uso consciente desse fenômeno.

A enfermagem radiológica é a especialidade responsável pelo atendimento ao cliente nos períodos pré, intra e pós-procedimento radiológico. Contudo, para a realização adequada desse atendimento, é necessário que o profissional possua conhecimentos teóricos e habilidades técnicas específicas dessa área de atuação (Sousa, 2011; Flôr e Kirchhof, 2006). Essa especialidade é regulamentada pelas resoluções n. 389/2011 e n. 418/2011 do Conselho Federal de Enfermagem (Cofen), que tratam, respectivamente, das especializações dos profissionais de nível superior e médio da equipe de enfermagem. 
Devido à evolução da tecnologia, cada vez mais os procedimentos de saúde tendem a utilizar equipamentos emissores de radiação ionizante em prol de um diagnóstico mais preciso; consequentemente, a atuação dos profissionais da enfermagem tende a crescer também nesse segmento (Flôr e Kirchhof, 2006).

Em vista disso, esta pesquisa foi norteada pela seguinte questão central: como contribuir para que a enfermagem tenha seus direitos assegurados no processo de trabalho envolvendo o diagnóstico por imagem, no que se refere ao processo educacional?

Para responder a essa questão, os objetivos da pesquisa foram: capacitar os discentes de um Curso Técnico em Enfermagem, na modalidade do Programa Nacional de Integração da Educação Básica com a Educação Profissional (Proeja), de uma instituição pública da Grande Florianópolis, no estado de Santa Catarina, sobre o processo de trabalho envolvendo práticas em diagnóstico por imagem; investigar a percepção dos discentes do Curso Técnico em Enfermagem-Proeja sobre as práticas do processo de trabalho em diagnóstico por imagem; verificar de que forma o processo de trabalho na área do diagnóstico por imagem é contemplado no Projeto Pedagógico do Curso (PPC) do Curso Técnico em Enfermagem-Proeja.

\section{Materiais e métodos}

Esta pesquisa ${ }^{3}$ utilizou como caminho metodológico a pesquisa-ação de natureza educativa, que teve como finalidade desenvolver o aprimoramento educacional tanto das pesquisadoras quanto dos participantes da pesquisa (Tripp, 2005).

A pesquisa-ação refere-se a um tipo de investigação/ação. Esse termo é utilizado para qualquer processo que segue um ciclo, buscando-se o aprimoramento da prática pela ação no seu campo e da investigação a seu respeito. Esse ciclo envolve planejamento, implantação, descrição e avaliação de mudanças na prática, buscando a solução do problema que envolve a pesquisa de uma maneira minuciosa (Tripp, 2005). O ciclo que norteou a pesquisa está demonstrado no diagrama da figura 1 . 
Figura 1

Ciclo da pesquisa

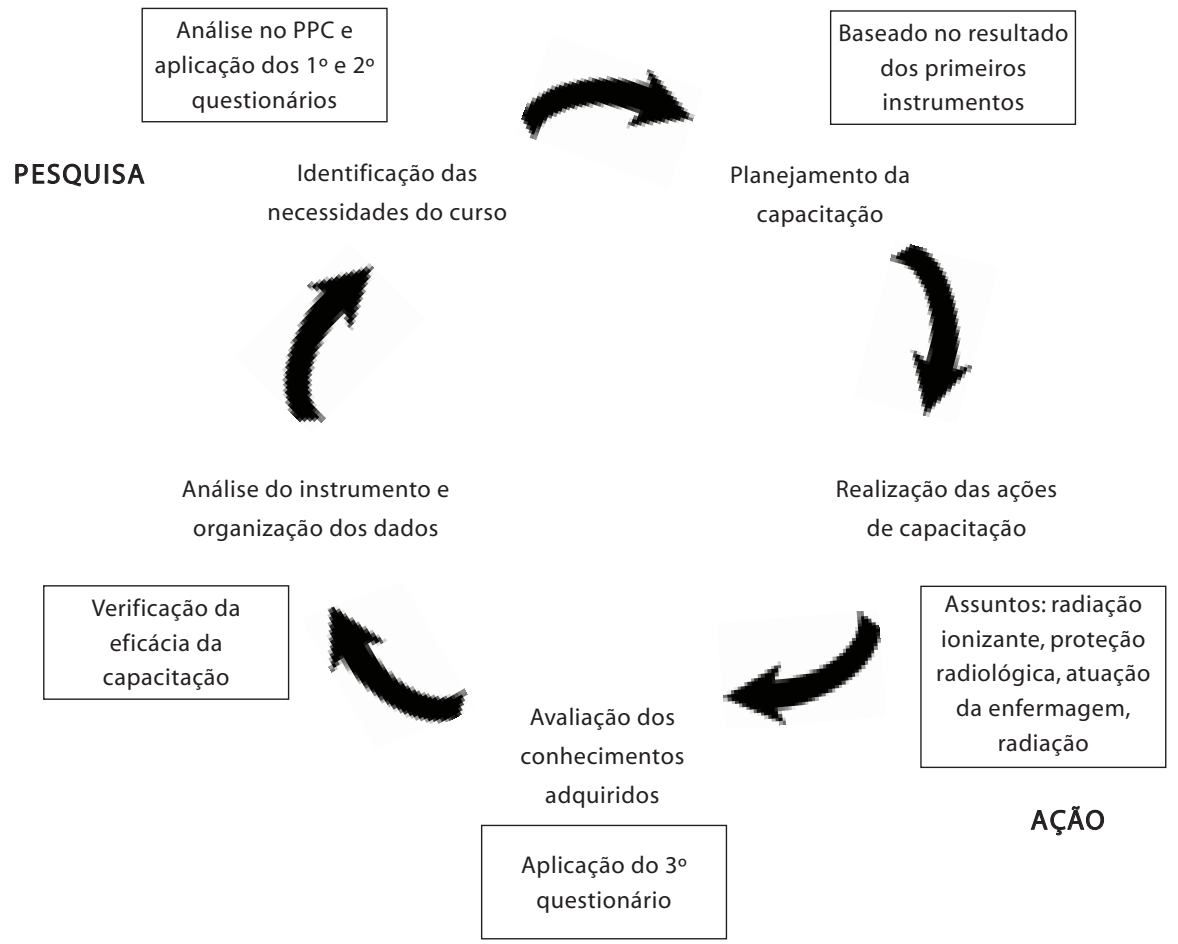

Fonte: Adaptado de Tripp, 2005

Nota: PPC - projeto pedagógico do curso.

Durante o desenvolvimento da pesquisa, integraram o grupo 23 participantes, sendo 14 discentes e 9 docentes do Curso Técnico em Enfermagem, na modalidade Proeja. A coleta dos dados e a realização da capacitação ocorreram no período de dezembro de 2011 a maio de 2012.

A pesquisa foi delineada por meio da coleta de dados de fontes documentais e de questionários semiestruturados, aplicados aos participantes da pesquisa. A coleta dos dados foi dividida em duas etapas:

a) dados existentes: essa etapa consistiu na análise documental do PPC, realizada na busca por informações sobre a abordagem do tema radiação ionizante no Curso Técnico em Enfermagem. A análise teve como objetivo verificar se o plano do curso apresenta uma programação que abra espaço para o fornecimento de informações aos alunos quanto à assistência prestada pelos técnicos em enfermagem nos serviços de radiologia e diagnóstico por imagem; b) dados originais: para a realização dessa etapa, foram elaborados três questionários com questões abertas e fechadas, dois deles direcionados aos 
discentes do curso e o outro, aplicado aos docentes. A aplicação dos questionários teve como objetivo levantar quais são as reais necessidades da abordagem da temática radiação ionizante e proteção radiológica no Curso Técnico em Enfermagem-Proeja e, posteriormente, avaliar os conhecimentos adquiridos durante as ações de capacitação e qual a importância da sua realização para a formação do aluno. Os dados foram tratados em planilhas eletrônicas.

O planejamento da capacitação ocorreu por meio da análise dos resultados obtidos com os dois primeiros questionários. Esse planejamento elencou o conteúdo a ser ministrado, a metodologia a ser adotada e o real objetivo da realização da capacitação. Foram solicitados à coordenação do Curso Técnico em Enfermagem-Proeja dois períodos de aula, de duas horas, em dois dias, para a sua execução. Quanto à sua realização, foram ministradas aulas expositivas e dialogadas. Os conteúdos estudados foram referentes às tecnologias em diagnóstico médico por imagem, radiação ionizante em centro cirúrgico, competências do técnico em enfermagem nesses serviços, radioproteção e legislação.

A pesquisa foi aprovada pelo Comitê de Ética em Pesquisa do Hospital Governador Celso Ramos.

\section{Resultados}

Os resultados obtidos foram dispostos em categorias e organizados por meio eletrônico. Ao final da análise dos questionários, os dados emergentes foram compilados e expostos da seguinte maneira: currículo do curso técnico em enfermagem; necessidade dos discentes; percepção dos docentes; e monitoramento e avaliação da capacitação.

\section{Currículo do curso técnico em enfermagem}

O Curso Técnico em Enfermagem-Proeja possui articulação integrada com o ensino médio. Anualmente, são abertas 60 vagas para ingresso no curso, sendo 30 novas vagas a cada semestre letivo. Os interessados devem obedecer a dois requisitos: possuir idade igual ou superior a 21 anos e ter completado o ensino fundamental.

A carga horária total do curso é de 2.400 horas. Destas, 600 horas são destinadas ao estágio curricular supervisionado. O curso é divido em seis fases ou três módulos, perfazendo 400 horas por fase ou 800 horas a cada módulo. A carga horária total equivale a três anos letivos. O limite mínimo para a formação do curso é de seis semestres, que correspondem à 
conclusão de uma fase por semestre, e o limite máximo para o término é de 12 semestres.

Cada módulo do Curso Técnico em Enfermagem-Proeja corresponde a um nível de conhecimento: vida e saúde, no primeiro módulo; assistência à saúde coletiva, no segundo; e assistência à saúde em todas as fases evolutivas, no terceiro.

Na terceira fase do curso, com carga horária de 40 horas/aula, os alunos passam por uma unidade curricular denominada Biossegurança, que possui como eixo principal a biossegurança e a radioproteção, a qual trata dos riscos ocupacionais relativos aos trabalhadores de enfermagem e das normas e regulamentos técnicos. Nesse período, é feita a abordagem da resolução n. 211/1998, que regulamenta a atuação dos profissionais da enfermagem em serviços de radiologia e diagnóstico por imagem. As habilidades inerentes a essa unidade curricular correspondem à aplicação dos princípios de biossegurança e radioproteção, visando à sua própria saúde e proteção, bem como à de seus pacientes. No entanto, nessa unidade curricular, apesar de serem abordados os tópicos sobre radiação ionizante e sobre a atuação do profissional de enfermagem nessa área, há pouco aprofundamento acerca do tema, pois a carga horária da unidade curricular é muito reduzida para que seja possível abordar os inúmeros assuntos da práxis desses profissionais nos serviços de radiologia e diagnóstico por imagem.

Das unidades curriculares que compõem o PPC do curso, três podem ser destacadas como funções do técnico em enfermagem que geralmente envolvem a exposição ocupacional à radiação ionizante. São elas: Clínica Médica e Cirúrgica e Unidade de Terapia Intensiva (UTI), nas $5^{\text {a }}$ e $6^{\text {a }}$ fases, correspondendo, cada uma delas, a 120 horas/aula; e Farmacologia, na $6^{\text {a }}$ fase, com uma unidade de 40 horas/aula.

A unidade curricular Clínica Médica e Cirúrgica é ministrada na $5^{\text {a }}$ fase, com carga horária de 40 horas/aula, e na $6^{\text {a }}$ fase, com carga horária de 80 horas/aula. Os conhecimentos envolvidos na disciplina vão desde as diversas patologias que acometem o ser humano até os fundamentos da enfermagem no serviço de saúde. Ao final dessa fase os alunos devem desenvolver as habilidades e competências do técnico em enfermagem que atendam às necessidades de conforto, segurança, higiene, alimentação, hidratação, eliminação e terapias do paciente internado, sendo realizada prática supervisionada em ambiente de clínica médica e cirúrgica.

A unidade curricular referente à UTI também é dividida entre as $5^{\mathrm{a}}$ e $6^{\mathrm{a}}$ fases, com carga horária de 40 horas/aula e 80 horas/aula, respectivamente. Seu objetivo é disseminar conhecimentos de agravos à saúde, legislação, regulamento do suporte nutricional, normas e rotinas em UTI e adminis- 
tração de medicamentos, desenvolvendo as habilidades para tal. Novamente, há a realização de prática supervisionada em UTI.

Percebe-se que nas unidades curriculares de Clínica Médica e Cirúrgica e de UTI a questão sobre exposição à radiação ionizante de profissionais da enfermagem em serviços de radiologia e diagnóstico por imagem não é contemplada nas ementas. E isso seria de extrema importância, porque são locais onde ocorre a maioria das exposições à radiação ionizante desses profissionais.

A unidade curricular de Farmacologia é ministrada em 40 horas/aula na $6^{\text {a }}$ fase do Curso Técnico em Enfermagem. Os conhecimentos referem-se aos cálculos e aos princípios de farmacologia, e as habilidades desenvolvidas visam calcular as dosagens corretas, reconhecer as diversas formas farmacêuticas e realizar a manipulação dos medicamentos. A apreensão desse conteúdo é de extrema importância para os profissionais que atuam em serviços de radiologia e diagnóstico por imagem, pois ele oferece subsídios para atuar com a aplicação dos meios de contraste, que são componentes necessários para melhor visualizar determinadas estruturas em alguns procedimentos. No entanto, o PPC do curso não aborda, especificamente, os meios de contraste em radiologia, os quais, por causa das suas especificidades, implicam a necessidade de um conhecimento específico, como as suas contraindicações e as possíveis reações adversas.

Após a conclusão do curso, os profissionais técnicos em enfermagem estão aptos para atuar em hospitais, clínicas e ambulatórios, como integrantes de equipes de saúde hospitalar, prestando assistência de enfermagem curativa; em unidades locais de saúde e na Estratégia Saúde da Família, na chamada assistência de enfermagem preventiva; em asilos, na enfermagem gerontológica; e na assistência de enfermagem domiciliar, a chamada home care.

Por fim, ressalta-se que a análise do currículo dos discentes do Curso Técnico em Enfermagem-Proeja aconteceu, exclusivamente, pela avaliação do PPC do curso, não tendo sido possível a observação da forma de abordagem desses temas pelos docentes em sala de aula, ou mesmo em campo, durante estágio supervisionado.

\section{Necessidade dos discentes}

O primeiro instrumento de pesquisa aplicado teve como objetivo avaliar o conhecimento científico e empírico dos discentes do Curso Técnico em Enfermagem-Proeja. Nessa etapa da pesquisa, 13 alunos responderam ao questionário, que visava avaliar o conhecimento dos participantes acerca de 
temas envolvendo a exposição à radiação ionizante e a proteção radiológica em seu processo de trabalho.

Sobre o significado da expressão radiação ionizante, apenas 9 participantes responderam à pergunta, com as seguintes respostas: "são raios provenientes de alguns exames diagnósticos" (5); "não sei" (3); e "é maléfica à saúde" (1). Assim, ficou evidente o desconhecimento dos alunos em relação ao que é a radiação ionizante; tal fato é preocupante em razão de haver uma larga escala de utilização desta nos serviços de saúde, como subsídios para diagnosticar e tratar diversas patologias que acometem o ser humano.

Ainda nesse contexto, todos os participantes da pesquisa responderam à questão sobre os danos causados pela exposição à radiação ionizante. Esse questionamento teve as seguintes respostas: "câncer" (8); “câncer e danos ao feto" (4); "câncer e envelhecimento" (1); e "ocorrência de danos no DNA, que causam mutações" também foi citada por um participante. Com isso, e fazendo referência a Flôr e Kirchhof (2006), diante das várias exposições dos profissionais da enfermagem que atuam na área do diagnóstico médico por imagem, percebe-se que esses profissionais não possuem informações básicas sobre o que é a radiação ionizante e quais os riscos que ela pode causar à saúde das pessoas.

Apesar de a maioria dos entrevistados não conhecerem o que é a radiação ionizante, muitos (10) já estiveram presentes em procedimentos envolvendo a sua emissão para fins diagnósticos, seja como acompanhantes ou como profissionais. Tal fato é preocupante diante do desconhecimento evidenciado nas respostas aos questionários, pois os exames de diagnóstico médico por imagem, apesar de apresentarem um crescimento contínuo ao longo dos anos, não têm os seus princípios bem compreendidos pelos profissionais da saúde, tais como os técnicos em enfermagem.

Dos pesquisados que já participaram de algum procedimento de natureza radiológica, obteve-se uma amostra de somente três discentes que afirmaram ter utilizado algum EPI contra a exposição à radiação. Os EPIs que podem ser utilizados para proteção da exposição à radiação ionizante, citados pelos participantes da pesquisa, foram "avental de chumbo" (12) e “óculos plumbífero" (1); uma pessoa não respondeu a essa pergunta.

O desenvolvimento da pesquisa também permitiu analisar a visão de cada pesquisado sobre os aparelhos de radiologia que emitem ou não radiação ionizante. Para verificarmos essa questão, solicitamos aos pesquisados que selecionassem, em uma lista, quais os aparelhos que emitiam radiação ionizante para fins diagnósticos. Com base nas respostas a essa questão, foi gerada a Tabela 1 . 
Tabela 1

\begin{tabular}{lcc}
\hline Aparelhos que emitem radiação ionizante & & \\
\hline Aparelho & $\mathbf{n}$ & $\%$ \\
\hline & & \\
Raios X & 12 & 20 \\
Ressonância magnética & 8 & 13 \\
Medicina nuclear & 4 & 7 \\
Eletrocardiograma & - & - \\
Tomografia computadorizada & 9 & 15 \\
Ultrassonografia & 5 & 8 \\
Densitometria óssea & 4 & 7 \\
Mamografia & 8 & 13 \\
Radioterapia & 10 & 17 \\
Endoscopia & - & - \\
Total & & 100 \\
\end{tabular}

Fonte: As autoras.

A Tabela 1 mostra o desconhecimento dos participantes da pesquisa quanto às tecnologias emissoras de radiação ionizante, visto que os aparelhos de ressonância magnética, selecionados por 8 participantes, e de ultrassonografia, mencionados por 5 participantes, não fazem uso da radiação ionizante. O restante dos aparelhos que são emissores de radiação ionizante, apontados pelos participantes, não foi escolhido como resposta por todos os alunos. A radiologia convencional, que utiliza o aparelho de raios $\mathrm{X}$ convencional, foi selecionada por 12 participantes; a medicina nuclear, que faz uso da radioatividade, por 4 alunos; a tomografia computadorizada, por 9; a densitometria óssea, foi citada por 4 participantes; a mamografia, por 8; e a radioterapia foi selecionada por 10 alunos. Somente o eletrocardiograma e a endoscopia não foram selecionados nessa questão, evidenciando uma resposta correta, pois não emitem radiação ionizante.

Sabemos que as atribuições dos profissionais de enfermagem de nível técnico no serviço de radiologia perpassam vários universos. A resolução n. 211/1998 do Cofen dispõe sobre as competências desses profissionais em serviços de radiologia e diagnóstico por imagem. Dentre as principais funções, podemos destacar as de executar ações de enfermagem em clientes submetidos a procedimentos envolvendo a radiação ionizante; atuar no âmbito da prevenção, tratamento e reabilitação dos pacientes submetidos à 
radiação ionizante; cumprir e fazer cumprir a legislação pertinente a essa área de atuação; e manter atualizações técnicas e científicas que lhe permitam atuar com eficiência na área da radiologia e diagnóstico por imagem. Todavia, mesmo constando no PPC do curso a abordagem dessa resolução durante as aulas de Biossegurança, verificaram-se nas respostas dos discentes as seguintes atribuições: "acompanhar", "auxiliar" e "orientar" os pacientes (8); "aplicar medicamentos, quando necessário" (2); e "fazer a reposição de materiais" (1), fato que mostra distorção sobre tais competências profissionais.

Questionamos a forma como o tema radiação ionizante é abordado no Curso Técnico em Enfermagem-Proeja, limitando a resposta a ser dada a essa pergunta por cada participante em insatisfatória, satisfatória e excelente; 10 participantes consideraram a abordagem do tema suficiente, e 3 consideraram insuficiente. Em contrapartida, 12 alunos afirmaram não estar preparados para assistir pacientes submetidos a procedimentos diagnósticos envolvendo a radiação ionizante e somente 1 sentiu-se seguro para atuar nesse serviço.

Percebe-se a necessidade de os futuros profissionais buscarem continuidade no processo de educação, com o intuito de alcançar uma melhor assistência aos pacientes que necessitam do serviço de diagnóstico médico por imagem. Contudo, a busca por atualização nem sempre acontece, principalmente nos serviços de radiologia e diagnóstico por imagem, os quais possuem saberes e práticas que são específicos no seu processo de trabalho. Apesar dessa necessidade especial de conhecimento científico, a educação continuada é pouco enfatizada (Flôr e Gelbcke, 2009).

\section{Percepção dos docentes}

O segundo questionário aplicado foi direcionado aos docentes do Curso Técnico em Enfermagem. O objetivo era verificar como os participantes viam a importância da abordagem dessa temática no curso. As questões relacionavam-se com a experiência dos docentes na área de enfermagem e o conhecimento sobre a especialidade de enfermagem radiológica, conforme prevê a resolução n. 418/2011 do Cofen.

O Curso Técnico de Enfermagem analisado conta com um corpo docente de 11 professores. A formação mínima é a graduação em Enfermagem. No entanto, apenas 9 docentes responderam ao questionário. O tempo de atuação dos profissionais varia entre 1 e mais de 15 anos, como está representado na Tabela 2. 
Tabela 2

\begin{tabular}{lcc}
\hline Tempo de atuação na área & n & $\%$ \\
\hline Tempo de trabalho & & \\
\hline & - & - \\
Até 1 ano & 3 & 33 \\
De 1 a 5 anos & 1 & 11 \\
De 5 a 10 anos & - & - \\
De 10 a 15 anos & 5 & 56 \\
Mais de 15 anos & & 100 \\
Total & & \\
\hline
\end{tabular}

Fonte: As autoras.

A carência no ensino da radiologia durante a formação em enfermagem também pôde ser percebida nos relatos dos docentes pesquisados, pois eles comentaram (8) que não obtiveram o conhecimento necessário para atuar em serviços de radiologia e diagnóstico por imagem ao cursarem a graduação. Apenas 1 docente afirmou ter recebido, poucas vezes, alguma orientação quanto à atuação nessa área.

De acordo com os docentes pesquisados, a abordagem do tema radiação ionizante e diagnóstico médico por imagem durante a formação dos futuros profissionais ocorre, principalmente, nos itens 'proteção ao trabalhador', 'cuidado aos pacientes submetidos aos procedimentos que envolvem exposição à radiação ionizante', 'orientação prestada a equipe e aos pacientes' e 'saber como agir na realização de tais procedimentos'.

Os docentes do Curso Técnico em Enfermagem-Proeja acreditam que os serviços de radiologia e diagnóstico por imagem da região ofertam trabalho aos profissionais da enfermagem (8), mas apenas um participante ressaltou que, às vezes, há essa oferta. Segundo Sousa (2011), em decorrência do grande avanço tecnológico sofrido pela radiologia nos últimos trinta anos, o papel dos profissionais de enfermagem na radiologia também evoluiu, e, atualmente, o enfermeiro radiológico é um elemento integral no cuidado dos indivíduos submetidos a procedimentos com radiação ionizante.

Os pesquisados foram questionados quanto ao fato de a enfermagem radiológica ser ou não praticada com consciência por parte dos profissionais. Essa pergunta obteve, em sua maioria, as seguintes respostas negativas: a enfermagem radiológica não é exercida com consciência pelos profissionais da 
enfermagem (5); às vezes essa assistência é prestada com consciência (2); outros dois participantes acreditam que os profissionais da enfermagem assistem com consciência os pacientes submetidos a procedimentos radiológicos.

Aos participantes que afirmaram que os profissionais da enfermagem não praticam com consciência a assistência em radiologia e diagnóstico por imagem, solicitamos que relacionassem o que seria necessário para mudar essa realidade. Com isso, obtivemos respostas como: "qualificação ou educação permanente continuada", "capacitação para os estudantes e os profissionais" e "implantação de uma disciplina voltada para a enfermagem radiológica no PPC do curso". Desta forma, deparamo-nos, novamente, com o estudo de Sousa (2011), quando afirma que, com as mudanças na radiologia, e, consequentemente, na atuação dos enfermeiros radiológicos, uma série de questionamentos deve ser levantada quanto ao futuro dessa especialidade, tais como: "para onde está indo a enfermagem radiológica?"; "como vamos chegar lá?"; "que habilidades serão necessárias nesse ambiente dinâmico: preparação educacional, programas de orientação?"; e "como vamos nos preparar para essa forma de trabalho no futuro?".

A especificidade da área da radiologia e diagnóstico por imagem requer, dos futuros profissionais, grande envolvimento com a literatura específica da área, bem como com cursos de especialização. Grande parte dos docentes que responderam ao questionário (7) afirmou não possuir conhecimento de qualquer literatura específica para enfermagem radiológica - somente 2 professores afirmaram ter esse conhecimento. Por outra parte, quanto aos cursos de especialização, somente 1 docente conhecia algum curso específico, enquanto 4 não possuíam essa informação e os outros 4 nem mesmo conheciam a especialidade enfermagem radiológica.

\section{Monitoramento e avaliação da capacitação}

As ações de capacitação dos discentes do Curso Técnico em Enfermagem-Proeja foram executadas visando às necessidades expostas pelos alunos e docentes do referido curso. Buscamos enfatizar e esclarecer as dúvidas apresentadas pelos participantes acerca do que é a radiação ionizante e qual a sua importância nos serviços de saúde, citando seus malefícios à saúde do trabalhador ocupacionalmente exposto e as precauções a serem tomadas a fim de se proteger contra a exposição desnecessária à radiação ionizante. Dessa maneira, a capacitação foi realizada atendendo às reais necessidades quanto ao processo de trabalho dos técnicos em enfermagem nos serviços de radiologia e diagnóstico por imagem.

Após a realização das ações de capacitação, outro questionário foi proposto aos discentes do Curso Técnico em Enfermagem-Proeja com o objetivo de avaliar os conhecimentos adquiridos por eles e a importância dessa 
prática para a sua formação. As questões abordadas buscaram avaliar como os participantes se sentiam em relação a essa questão antes da capacitação, e como passaram a vê-la depois de sua realização.

Todos os pesquisados concordaram que a exposição à radiação ionizante é prejudicial ao ser humano. Quanto à proteção radiológica em ambiente hospitalar, listou-se uma série de precauções que podem ser tomadas pelo profissional exposto a fim de se proteger dela (Tabela 3), o que demonstra o conhecimento dos discentes pesquisados.

Tabela 3

\begin{tabular}{lcc}
\hline Proteção contra a radiação ionizante & & \\
\hline Procedimento & $\mathrm{n}$ & $\%$ \\
\hline & 3 & 11 \\
Sair da sala & 14 & 50 \\
Vestimenta adequada & - & - \\
Esconder-se atrás de cortinas & 11 & 39 \\
Utilizar dosímetro & & 100 \\
Total & & \\
\hline Fonte: As autoras. & &
\end{tabular}

Diferentemente das respostas obtidas no primeiro questionário, quando 12 discentes afirmaram não se sentir preparados para atuar em um serviço de radiologia e diagnóstico por imagem, no segundo questionário, aplicado após a realização das ações de capacitação, eles se mostraram mais confiantes para atuar nessa área, com oito respostas afirmativas e seis negativas.

Os participantes da pesquisa foram questionados quanto à importância da oferta de conhecimentos acerca do processo de trabalho da enfermagem em serviços de radiologia e diagnóstico por imagem. Todos os 14 discentes afirmaram que a oferta de cursos de capacitação/extensão em enfermagem radiológica é importante para a atuação em tais serviços.

Paralelamente, 12 participantes consideraram a realização da capacitação discente no processo de trabalho em diagnóstico por imagem do técnico em enfermagem muito importante para o seu processo de formação, 1 participante considerou importante e 1 considerou pouco importante.

Finalmente, notou-se a necessidade de os alunos receberem esse tipo de orientação durante o processo de aprendizagem, visto terem demonstrado certa curiosidade e vontade de entender melhor a temática. A realização de atividades como essa pode melhorar a aprendizagem e o desempenho dos estudantes (Hama e Kusano, 2005). 


\section{Considerações finais}

Constatou-se que, apesar de a abordagem do tema radiação ionizante constar no PPC do Curso Técnico em Enfermagem-Proeja, bem como da resolução n. 211/1998 do Cofen, a carga horária disponibilizada é insuficiente para que sejam abordadas todas as características específicas desta área. Sendo assim, existem fragilidades na formação do técnico em enfermagem para atuar no serviço de radiologia e diagnóstico por imagem.

Além disso, verificou-se uma debilidade na formação dos futuros profissionais, em vista de não haver aproximação com o tema nas unidades curriculares de Clínica Médica e Cirúrgica, UTI e Farmacologia. Essas são áreas de atuação do técnico em enfermagem que envolvem a maior exposição à radiação ionizante no ambiente hospitalar, ou mesmo onde esse profissional é responsável por repassar diversas informações, referentes aos procedimentos realizados, aos pacientes que se encontram sob sua assistência.

Ficou evidente o desconhecimento dos alunos em relação aos princípios básicos da radiação ionizante e proteção radiológica. Tal fato é preocupante em razão de haver uma larga escala de utilização de radiação ionizante nos serviços de saúde, como subsídio para diagnosticar e tratar diversas patologias que acometem o ser humano. Paralelamente, antes da realização das ações de capacitação, os discentes afirmaram, em sua grande maioria, sentir-se despreparados para atuar no serviço de radiologia e diagnóstico por imagem, o que pode estar relacionado ao fato de essa disciplina não ter sido abordada durante a sua formação.

A pesquisa permitiu visualizar a existência de uma lacuna na abordagem de questões envolvendo o diagnóstico médico por imagem na formação dos docentes do Curso Técnico em Enfermagem-Proeja, que, reconhecendo oferecer essa área de atuação espaço para a assistência dos técnicos em enfermagem, relataram a importância desse conhecimento para a formação profissional dos alunos. No entanto, a implantação de um processo de aprendizagem em enfermagem radiológica é dificultada por ser escassa a literatura na área. Poucas são as publicações referentes ao tema. $\mathrm{O}$ mesmo pode-se afirmar quanto à oferta de cursos de especialização/extensão, os quais estão limitados à região Sudeste.

Apesar disso, é imperiosa a qualificação dos técnicos em enfermagem que pretendem atuar em serviços de radiologia e diagnóstico por imagem. Somente com a garantia de domínio do conhecimento científico específico e da técnica utilizada realizar-se-á uma assistência adequada e de qualidade aos pacientes que necessitam submeter-se a um procedimento radiológico.

Posteriormente à realização das ações de capacitação dos futuros profissionais, verificou-se que eles adquiriram alguns conhecimentos básicos sobre os princípios físicos da radiação ionizante e a atuação dos profissionais 
da enfermagem nessa área do conhecimento, bem como se mostraram mais seguros para prestar assistência nesse campo. Em razão disso, acreditamos que, com a realização da capacitação, alcançamos nosso objetivo de disseminar o conhecimento necessário para esses futuros profissionais da área da saúde.

Todavia, a análise dos resultados coletados levou a questionamentos sobre a atuação dos profissionais da saúde que não fazem parte de processo de aquisição (profissionais das técnicas radiológicas) ou de interpretação (radiologistas) das imagens radiológicas, os quais já atuam nos serviços de radiologia e diagnóstico por imagem. Foram eles: como esses profissionais se preparam para prestar essa assistência? Em algum momento é repassada aos alunos essa informação, seja em sala de aula ou na prática supervisionada? Quais conhecimentos são importantes para essa atuação? Deixamos a resposta a essas indagações para pesquisas futuras.

Resumen El papel de la enfermería radiológica creció de manera significativa, volviendo a este profesional un elemento esencial en radiología y diagnóstico por imagen. Considerando que un profesional con fragilidades en su calificación se expone a riesgos innecesarios, la importancia de este trabajo es el resultado de la necesidad de divulgar conocimientos acerca de la especialidad a futuros profesionales. El objetivo de este artículo es conocer el proceso de trabajo en diagnóstico por imagen de los estudiantes del Curso Técnico en Enfermería - Proeja, en una institución pública de la Gran Florianópolis, en el estado de Santa Catarina. La metodología utilizada fue la investigación-acción. Se aplicaron tres cuestionarios a los estudiantes y docentes del curso, a fin de conocer las necesidades del curso con relación al tema. Los resultados revelaron un desfasaje en la formación puesto que no se aborda la temática en las clases. Con base en las necesidades expuestas por los participantes en la investigación, las acciones de capacitación se planificaron abordando temas como radiación ionizante, protección radiológica, papel del técnico en enfermería en el área y legislación. Después de la capacitación, los alumnos presentaron mayor seguridad e interés en actuar en los servicios de diagnóstico por imagen, así como en mantener un proceso de educación continua. Por lo tanto, la realización de la capacitación resultó ser pertinente para la formación de los futuros profesionales.

Palabras clave Radiología; educación en enfermería; trabajo. 


\section{Notas}

1 Instituto Federal de Educação, Ciência e Tecnologia de Santa Catarina (IF-SC), Florianópolis, Santa Catarina, Brasil.

Mestranda em Enfermagem na Universidade Federal de Santa Catarina (UFSC).

$<$ julianac@ifsc.edu.br>

Correspondência: Rua Pedro Fernandes, 509, Carianos, Florianópolis, Santa Catarina, Brasil, CEP 88.047-624.

2 Instituto Federal de Educação, Ciência e Tecnologia de Santa Catarina (IF-SC). Florianópolis, Santa Catarina, Brasil.

Graduanda no Curso Superior de Tecnologia em Radiologia pelo IF-SC.

$<$ franciele_cvargas@yahoo.com.br>

3 Resultado de projeto de iniciação científica do edital PRPPGI n. 11/2011 do Instituto Federal de Educação, Ciência e Tecnologia de Santa Catarina, financiado pelo Conselho Nacional de Desenvolvimento Científico e Tecnológico ( $\mathrm{CNPq})$ e aprovado pelo Comitê de Ética em Pesquisa do Hospital Governador Celso Ramos, Florianópolis, Santa Catarina, Brasil, sob o parecer n. 2011/0065.

\section{Referências}

BRASIL. Lei n. 7498, de 25 de junho de 1986. Dispõe sobre a regulamentação do exercício da enfermagem e dá outras providências. Diário Oficial da União, Brasília, DF, 26 jun. 1986. Seção 1, p. 9.273-9.275.

Resolução Cofen n. 389, de 20 de outubro de 2011a. Atualiza, no âmbito do sistema Cofen/Conselhos Regionais de Enfermagem, os procedimentos para registro de título de pós-graduação lato e stricto sensu concedido a enfermeiros e lista as especialidades. Diário Oficial da União, Brasília, DF, 20 out. 2011 . Seção 1, p. 146.

Resolução Cofen n. 418, de 29 de novembro de $2011 \mathrm{~b}$. Atualiza, no âmbito do sistema Cofen/Conselhos Regionais de Enfermagem, os procedimentos para registro de especialização técnica de nível médio em enfermagem. Diário Oficial da União, Brasília, DF, 6 dez. 2011. Seção 1, p. 78-79.
Conselho Federal de Enfermagem (Cofen). Resolução Cofen n. 211, de 1 de junho de 1998. Dispõe sobre a atuação dos profissionais de enfermagem que trabalham com radiação ionizante. Brasília: Cofen, 1998.

. Conselho Nacional de Saúde. Resolução n. 196/96. Diretrizes e normas regulamentadoras de pesquisa envolvendo seres humanos. Diário Oficial da União, Brasília, DF, 16 out. 1996. Disponível em: <www.cep. ufsc.br>. Acesso em: 14 maio 2012.

DELORS, Jacques et al. Os quatro pilares da educação. In: . DELORS, Jacques et al. Educação: um tesouro a descobrir. Relatório para a Unesco da Comissão Internacional sobre Educação para o Século XXI. São Paulo: Cortez, 2000. p. 89-102.

FLÔR, Rita de C.; GELBCKE, Francine L. Tecnologias emissoras de radiação ionizante 
e a necessidade de educação permanente para uma práxis segura da enfermagem radiológica. Revista Brasileira de Enfermagem, Brasília, v. 62 , n. 5, p. 766-770, set./out. 2009.

; KIRCHHOF, Ana L. C. Uma prática educativa de sensibilização quanto à exposição à radiação ionizante com profissionais de saúde. Revista Brasileira de Enfermagem, Brasília, v. 59, n. 3, p. 274-278, maio/jun. 2006.

HADDAD, Ana E. et al. (Org.). A trajetória dos cursos de graduação na área da saúde: 1991-2004. Brasília: Inep, 2006.

HAMA, Yukihiro; KUSANO, Shoichi. Teaching Radiology to Military Nursing Students. Military Medicine, Bethesda, v. 170, p. 713-714, Aug. 2005.

PIRES, Denise. A enfermagem enquanto disciplina, profissão e trabalho. Revista Brasileira de Enfermagem, Brasília, v. 62, n. 5, p. 739-744, set./out. 2009.
SALES, Orcélia P. et al. Atuação de enfermeiros em um centro de diagnóstico por imagem. Journal of the Health Sciences Institute, São Paulo, v. 28, n. 4, p. 325-328, 2010.

SOUSA, Mary F. Management and Leadership: Educating and Orienting the Radiology Nurse of the Future. Journal of Radiology Nursing, Filadélfia, v. 30, n. 3, p. 135-136, 2011.

TRIPP, David. Pesquisa-ação: uma introdução metodológica. Educação e Pesquisa, São Paulo, v. 31, n. 3, p. 443-466, set./dez. 2005.

VASCONCELLOS, E. M.; FROTA, Lia H.; SIMON, Eduardo. Perplexidade na universidade: vivência nos cursos de saúde. São Paulo: Hucitec, 2006.

Recebido em 18/07/2012

Aprovado em 22/10/2012 